\title{
Análise da Produção sobre a Síndrome de Burnout em Professores, de 2002 a 2013
}

\author{
Maria Paula Silvestre Campelo ${ }^{1}$; Sidney Medeiros de Oliveira ${ }^{2}$
}

\begin{abstract}
Resumo: O presente estudo é uma revisão sistemática da literatura sobre a Síndrome de Burnout em professores. O objetivo principal foi averiguar como este tema vem sendo abordado nos últimos anos e, discutir sobre as conclusões dos autores com relação a esta temática. A Síndrome de Burnout é um tipo particular de estresse, que influencia diretamente na qualidade de vida e de trabalho dos professores. Suas principais características são o esgotamento físico e emocional, conseqüências de desgaste psicológico e físico, provocados por condições e/ou situações percebidas como desagradáveis e desmotivadoras no ambiente laboral. Muitos sintomas podem ser desencadeados à partir da síndrome, tais como: irritabilidade, perda momentânea da memória, sensação de cansaço e fadiga, podendo chegar a uma depressão profunda. Para a realização do presente estudo, foram selecionados 29 artigos à partir das palavras-chave, pelo título: burnout, estresse laboral, professores, educadores, na base de dados Scielo. Desse total, apenas 20 atenderam aos critérios de inclusão. As conclusões contidas nesta revisão, certamente nortearão políticas públicas de saúde para os docentes, ao tempo em que incentiva novos estudos e discussões sobre a melhoria da qualidade de vida e labor dos educadores.
\end{abstract}

Palavras-chave: Síndrome, Burnout, Estresse, Professores

\section{Analysis of Production on Burnout Syndrome in Professors from 2002 to 2013}

\begin{abstract}
The present study is a systematic review of the literature on burnout syndrome in professors. The main objective was to verify how this issue has been discussed in the past years and discuss the authors' conclusions regarding this issue. The Burnout Syndrome is a particular type of stress, which directly influences the quality of life and work of professors. Its main characteristics are the physical and emotional exhaustion, psychological and physical consequences of wear caused by conditions and / or situations perceived as unpleasant and demotivating in the work environment. Many symptoms can be triggered from the syndrome, such as irritability, momentary loss of memory, sensation of tiredness and fatigue, reaching in a deep depression. To conduct the present study, 29 items from the keywords, based on SciELO data: Burnout, work stress, professors, educators title were selected. Of this total, only 20 met the inclusion criteria. Conclusions contained in this review certainly will guide public health policies for professors, at the time that encourages further studies and discussions on improving the quality of life and labor educators.
\end{abstract}

Keywords: Syndrome, Burnout, Stress, Professors

\section{Introdução}

Burnout, é uma expressão inglesa que quer dizer "queimar-se" ou "consumir-se pelo fogo", foi utilizada pela semelhança com o estado de esgotamento emocional (estar consumido), este fenômeno é vivenciado mais frequentemente e intensamente por categorias profissionais que envolvem o cuidado com o outro.

\footnotetext{
${ }^{1}$ Graduação em Recursos Humanos e Especialização em Gestão Estratégica de Pessoas pela Faculdade Leão Sampaio - CE. Mestranda em Ciências da Educação Pela Universidade Lusófona de Humanidades e Tecnologias de Lisboa - PT. E-mail: paulascampelo@ hotmail.com. ${ }^{2}$ Educador Físico pela Universidade Federal de Pernambuco. Doutorando em Ciências da Saúde pela Faculdade de Medicina do ABC - São Paulo. E-mail: meolli@hotmail.com.
} 
A Síndrome de Burnout(SB) é um transtorno adaptativo crônico associado a um inadequado enfrentamento dos problemas do dia-a-dia e das demandas do trabalho. Está associado à produção de efeitos negativos na qualidade de vida da pessoa e, no caso dos professores a uma perda de qualidade da prestação dos serviços (CARLOTTO e PALAZZO, 2006).

O burnout foi reconhecido como um risco ocupacional para profissões que envolvem cuidados com saúde, educação e serviços humanos (Golembiewski, 1999; Maslach, 1998; Murofuse et al., 2005). No Brasil, o Decreto no 3.048, de 6 de maio de 1999, aprovou o Regulamento da Previdência Social e, em seu Anexo II, trata dos Agentes Patogênicos causadores de Doenças Profissionais. O item XII da tabela de Transtornos Mentais e do Comportamento Relacionados com o Trabalho (Grupo V da Classificação Internacional das Doenças - CID-10) cita a "Sensação de Estar Acabado" ("Síndrome de Burnout", "Síndrome do Esgotamento Profissional") como sinônimos do burnout, que, na CID-10, recebe o código Z73.0.

O burnout encontra-se na atualidade entre as enfermidades emergentes. Foi descrita pela primeira vez no ano de 1974 nos Estados Unidos. Este feito foi levado a cabo por Herbert Freudenberger, a partir de estudos sobre a perda de motivação e comprometimento, acompanhados de sintomatologias psíquicas e físicas, como e perda de energia e a presença de fadiga, manifestados por voluntários de uma instituição para tratamento de drogados Freudenberger \& Richielson, 1980; Schaufelli \& Buunk, 1996). Não obstante, quase paralelamente, Christina Maslach também utilizou a expressão burnout como resultado da pesquisa sobre influência da carga emocional do trabalho no comportamento de profissionais de saúde, assistentes sociais e advogados (MASLACH e JACKSON, 1981,1985).

Com o advento das mudanças no panorama profissional, decorrentes da Era da Informação e o crescimento da tecnologia surgem um novo histórico de doenças como: estresse, ansiedade, depressão e a Síndrome de Burnout, que figuram no nosso dia a dia em consequência do aumento da carga horária de trabalho, exigência de consecução de metas crescentes e que condicionam o salário do trabalhador(professor), o assédio e às intimidações, além da carga de trabalho burocrático obrigatório a que são submetidos além da sala de aula.

A presente revisão sistemática de literatura se propõe a verificar como a Síndrome de Burnout em professores vem sendo abordada na literatura nos últimos dez (10) anos, mais especificamente de 2002 a 2013. Através de vinte e nove (29) artigos em Língua Portuguesa obtidos de modo aleatório nas bases de dados Scielo, Bireme, Biblioteca Virtual em Saúde - BVS e Google Acadêmico, com base nas seguintes palavras chave: estresse, síndrome de burnout, esgotamento físico, desgaste emocional, fadiga. Os artigos obtidos depois revisados através uma leitura inicialmente superficial, para depois serem procedidas leituras mais aprofundadas, a fim de categorizar os artigos selecionados. Dos 28 artigos obtidos sete (7) foram descartados não se enquadrarem nos critérios de 
inclusão e, dois (02) apenas utilizavam o termo em outra temática. Deste modo, foram selecionados (20) por estarem de acordo com os critérios já descritos, sendo a maior parte de relatos de pesquisa (Tabela 1).

Tabela 1 - Distribuição da produção por categoria (2013)

\begin{tabular}{l|c|c}
\multicolumn{1}{c|}{ Categorias } & $\mathbf{N}$ & $\mathbf{( \% )}$ \\
\hline Relato de Pesquisa & 13 & 65,0 \\
\hline Análise de publicações & 06 & 30,0 \\
\hline Validação de Instrumento & 01 & 5,0 \\
\hline Total & 20 & 100,0 \\
\hline
\end{tabular}

Dos artigos selecionados, um artigo foi do ano de 2002, um do ano de 2003, um artigo do ano de 2005, dois artigos do ano de 2006, dois artigos do ano de 2007, um artigo do ano de 2008, dois artigos do ano de 2009, três artigos do ano de 2010, três artigos do ano de 2011, três artigos do ano de 2012 e um artigo do ano de 2013.

Considerando a proporção de ocorrência de Síndrome de Burnout, o presente estudo justifica-se por ser uma forma de subsidiar estudos futuros, que possam chamar a atenção de autoridades para a necessidade de políticas públicas que ofereçam assistência psicológica aos profissionais de educação.

Assim, objetivo desta revisão sistemática foi analisar os artigos sobre Síndrome de Burnout em Professores, produzidos de 2002 a 2013 e discutir os pontos mais citados nos mesmos, como forma de propiciar políticas assistenciais aos profissionais docentes, descrevendo os artigos e suas origens (nacionalidade, periódico, população estudada), bem como analisar a prevalência da Síndrome de Burnout em professores e subsidiar novos estudos.

\section{Discussão}

\section{Categoria 1 Validação de Instrumento}

A categoria de Validação de Instrumento apresentou apenas um, dos vinte artigos selecionados. 
Este se refere aos professores como sendo das profissões mais propensas ao estresse e burnout.

Devido às especificidades da profissão foi desenvolvido o "Cuestionario de Burnout do Profesorado" - (CBP) CBP- Revisado que mede o mesmo fenômeno que o Maslach Burnout Inventory -(MBI- Ed), permitindo analisar as diferentes fases do processo, com a finalidade de completar aspectos característicos da organização escolar e atividades de ensino.

$\mathrm{O}$ artigo explicita que a nova versão do CBP-R cumpriu o seu intento de modo satisfatório à linha teórica do MBI. Novamente comprovou-se a fiabilidade e a uniformidade interna de suas escalas, assim como sua validade em relação ao critério de burnout do MBI-Ed. Ambos os instrumentos medem o mesmo fenômeno psicológico, além disso, o CBP-R permite analisar as distintas fases do desenvolvimento da exaustão profissional e pode explicar em maior medida os sintomas dos examinandos.

Tendo o artigo através de aplicação comparada dos dois questionários citados constatado as garantias de confiabilidade e validade do CBP-R que aparece como instrumento alternativo para avaliar o desgaste profissional dos professores e seus fatores antecedentes. Da mesma forma, o MBIEd poderia analisar o processo, incluindo em sua medida os fatores desencadeantes do desgaste que configuram o CBP-R.

\section{Categoria 2 Relato de Pesquisa}

Na categoria Relato de pesquisa foram enquadrados 13, dos 20 artigos selecionados para compor este estudo. $\mathrm{O}$ que representou $65 \%$ dos artigos selecionados ao acaso.

Um dos artigos coletados ao acaso publicado no ano de 2003 objetivou analisar se o gênero estabelece diferenças significativas no processo e níveis da SB em professores de escolas da rede pública, ao passo que tencionou verificar a associação das dimensões do Burnout com variáveis demográficas, laborais, e comportamentais, através MBI alem de questionário específico. O estudo indicou a inexistência de diferença significativa entre grupos nas dimensões e níveis de Burnout, entretanto, o que se pode verificar foi a ocorrência da associação diferenciada nos dois grupos entre as dimensões e níveis de Burnout e determinadas variáveis demográficas, profissionais e comportamentais como: idade, tempo de serviço, questões culturais.

Do ano de 2007, foi coletado um artigo que pretendeu identificar os preditores da SB através de um questionário para levantamento das variáveis demográficas e profissionais, além MBI, o Job Diagnostic Survey e o Questionário de Satisfação no Trabalho. Os resultados obtidos na pesquisa apontaram que as condições de trabalho predominam no modelo explicativo de Burnout. 
$\mathrm{O}$ artigo em resumo diz que é importante estudar a cultura, inclusive profissional, peculiar em cada população por conta de sua peculiaridades pois, apresentam importantes e marcadas diferenças que influenciam nos resultados. Há diversidades sociais, culturais e econômicas ligados às profissão. Professores universitários possuem maior status que professores escolares. O artigo recomenda a realização de novos estudos com novas variáveis, a fim de ampliar a explicação deste fenômeno psicossocial.

Dos artigos coletados nesta categoria, apenas um foi do ano de 2008, este estudo quis identificar se há diferença na relação existente entre estratégias de enfrentamento e as dimensões de Burnout em professores de escolas públicas e privadas.

. Os resultados encontrados, evidenciam diferenças nas estratégias utilizadas. Em professores de escolas privadas, quanto maior a utilização de estratégias de confronto, maior a exaustão emocional e a despersonalização e quanto maior a utilização de aceitação de responsabilidade menor a realização profissional. Em professores de escolas públicas, quanto maior a utilização da estratégia de afastamento e de fuga, maior a exaustão emocional. A despersonalização eleva-se ao passo em que existe um maior uso da estratégia de afastamento. A resolução de problemas oferece elevação da dimensão de realização profissional. Os resultados indicam ser necessárias intervenções diferenciadas nos grupos pesquisados.

Um dos artigos do ano de 2006, buscou avaliar a síndrome de burnout em professores de escolas particulares e sua possível associação com fatores como, variáveis demográficas que se associam a SB, variáveis laborais que se associam à SB e fatores de estresse que se associam à SB. Através do MBI e outro questionário complementar direcionado às variáveis estudadas. Os resultados revelaram que professores apresentam nível baixo nas três dimensões que compõem burnout: exaustão emocional, despersonalização e diminuição da realização pessoal no trabalho. Variáveis demográficas não apresentaram relação com as dimensões de burnout, porém, das variáveis profissionais, a carga horária e a quantidade de alunos atendidos foram as que mostraram associação com a dimensão de exaustão emocional. Mau comportamento dos alunos, expectativas familiares e pouca participação nas decisões institucionais foram os fatores de estresse que apresentaram associação com as dimensões de burnout.

O que conclusivamente vem reforçar a afirmativa de que o alto nível de cobranças por se tornarem as escolas ambientes organizacionais, contribui de forma incontestável para o desenvolvimento da doença.

Outro artigo do mesmo ano, objetivou discutir e analisar a trabalho do docente em seu caráter intangível, face aos modelos de organização e gestão do trabalho atuais no fito de contribuir no debate a respeito da organização do trabalho do professor e sua disposição de luta contra a atual forma econômica e política hegemônica. 
A perda de sentido do trabalho e o sentimento de impotência para torná-lo mais significativo têm levado muitos trabalhadores, e em especial os professores, à síndrome de burnout, entendida como perda de energia no trabalho, mas também como um processo de despersonalização. As explicações sobre o que leva os trabalhadores a uma desolação em relação ao próprio trabalho e a si mesmos, podem ser várias. Através das pesquisas realizadas pelo referido artigo, as condições insalubres de trabalho e a falta de perspectivas profissionais dos docentes vêm corroborando fortemente para o abandono da profissão. A reestruturação produtiva e as reformas neoliberais em curso, voltada para a capitalização do ensino, representam mudanças que contribuem para a ampliação do burnout, em consequência da crescente cobrança do trabalho do professor.

$\mathrm{O}$ artigo evidencia a necessidade de se ultrapassar a descrição da síndrome da desistência como fenômeno crescente entre os professores.

Concluindo, os dois artigos referenciados apontam para o fato de que vivemos hoje a era da informação que se caracteriza, dentre outros fatores, pelo capitalismo exacerbado, competitividade, além de ser uma sociedades de organizações o que vem acontecendo também com o ensino e aumentando o nível de exigências aos professores que aumenta drenando sua qualidade de vida.

Ainda na categoria Relato de Pesquisa, foram obtidos na busca quatro artigos do ano de 2010, o primeiro aborda os conceitos de burnout feito através de uma pesquisa empírica a respeito do tema.

Em resumo, burnout é uma reação negativa que decorre de estresse prolongado no trabalho, fala ainda sobre os sintomas da SB, numa analise feita de estudos anteriores destacam-se os prevalência e que a maioria dos estudos publicados são aplicadas a profissionais de saúde e educação utilizam-se da definição de Maslach. Diz ainda, que no Brasil ainda há poucas publicações sobre burnout.

Concluindo, o artigo sente a carência de estudo nesta área e diversificação dos mesmos, pois importante se faz estudar não só a prevalência através questões estruturadas, mas de estudos que possibilitem vislumbrar os fatores de risco e consequências.

Outro artigo ano de 2010, realizou pesquisa no sentido de avaliar a relação entre Síndrome de Burnout, níveis de ensino e variáveis laborais. Foram analisados professores do ensino infantil, fundamental, médio e universitário. O resultado obtido foi que no ensino infantil os professores apresentam níveis menores de despersonalização e exaustão emocional que os demais. O nível médio tem maior nível de despersonalização que o infantil e o universitário. No tocante à realização profissional todos os níveis variam entre si, apontando para necessidade de ações diferenciadas conforme o nível de ensino.

O terceiro artigo do ano de 2010 obtido na busca para esta revisão sistemática, o estudo foi uma pesquisa qualitativa e objetivou investigar as manifestações sugestivas de burnout entre professores da rede pública e enfermeiros refletindo sobre o trabalho dos mesmos. Os dados foram 
coletados através de entrevistas. O estudo evidenciou a interface entre as duas áreas no que se refere ao contexto do ambiente onde o trabalho destes profissionais é desenvolvido.

Em resumo, o artigo ressalta a importância do método qualitativo para dar visibilidade ao interior de cada uma das categorias o que segundo o mesmo não alcançado pelos estudos feitos através de questionários estruturados.

No quarto e ultimo artigo do ano de 2010, avaliou a prevalência da SB em professores do ensino fundamental e sua relação com variáveis sócio-demográficas e laborais, concluindo que estas variáreis associam-se às dimensões de Burnout, através de resultados que apontaram que 33,6\% dos professores apresentam altos índices de Exaustão emocional, 8,3 alto nível despersonalização e 43,4 baixo nível de realização profissional. Indicando ser importante o reconhecimento desta síndrome como doença ocupacional e a criação de políticas públicas para a saúde e bem-estar docente.

Do ano de 2011 foram obtidos três artigos na presente categoria, o primeiro deles falou na prevalência e fatores associados através de uma pesquisa quantitativa realizada em professores instrumentalizada pelo MBI. Em conclusão, o artigo concluiu que mulheres, sem companheiro fixo, sem filhos, com carga horária elevada, que se dedicam a maiores número de discentes e que trabalham em escolas públicas apresentam maior risco de apresentarem SB.

Um artigo publicado em 2009 verificou a correlação entre a Qualidade de Vida no Trabalho (QVT) com Síndrome de Burnout em professores de educação física. Os resultados foram que a maioria dos professores encontra-se satisfeita com a qualidade de vida no trabalho, o descontentamento é com a remuneração e compensação. A exaustão emocional relatada pelos professores está ligada ás condições de trabalho, ao sentimento de segurança, à possibilidade de progressão na carreira, as garantias legais aos trabalhadores, ao tempo equilibrado entre trabalho e lazer. Concluindo, a realização profissional está ligada também aos sentimentos de estabilidade, à possibilidade de progressão na carreira e ao tempo para o lazer.

Na busca houve dois artigos nesta categoria do ano de 2012, o primeiro deles foi um estudo correlacional e comparativo entre participantes, considerando duas principais variáveis: Síndrome de Burnout e fadiga e estresse no trabalho e indicadores de situação de trabalho, através do MBI e os resultados revelaram que o estresse no trabalho tem implicações negativas, com a SB e a fadiga. O artigo ainda chama a atenção para necessidade de intervenções e de mais estudos junto a este grupo.

No outro estudo publicado também no ano de 2012, analisou a prevalência de Síndrome de Burnout nos professores médicos de uma universidade no ano de 2011, através de protocolos aplicados a 48 médicos docentes e concluiu que a prevalência de SB nos indivíduos estudados em 2011, foi bastante elevada, pois 50\% dos pesquisados possui a Síndrome.

Apenas um artigo publicado em 2013 foi encontrado na busca e avaliou as correlação dos níveis de burnout com as variáveis sociodemográficas em docentes que trabalham no ensino médio. 
As ferramentas utilizadas na pesquisa foram MBI-ED e uma Ficha Sociodemográfica. O que resultou em um índice gritante e 81,5\% da amostra acometida de burnout, estando 20,7\% em grau moderado e 60,8 em grau crônico. A baixa realização profissional foi apontada como a que mais contribui para a SB dentre as outras variáveis o que sinaliza a importância de políticas públicas que valorizem a educação e os educadores.

\section{Categoria 3 Análise de Publicações}

Nesta categoria foram elencados seis artigos dos vinte selecionados, perfazendo uma porcentagem de $35 \%$ do total dos construtos selecionados. Sendo um artigo do ano de 2005, um do ano de 2007, um artigo do ano de 2008, dois artigos do ano de 2011 e um artigo de 2012.

O estudo publicado no ano de 2005 buscou através de sessenta e um estudos publicados em base de dados, identificar características dos métodos e de intervenção de programas de manejo de estresse ocupacional, do que foi depreendido que a maioria dos relatos tem sido com profissionais da saúde e educação, porém com reduzido número de amostras. Conclusivamente, os programas com conteúdo multicomponente são os mais efetivos na redução de indicadores individuais, como ansiedade e depressão. Entretanto, a revisão sistemática em foco recomendou estudos acerca da efetividade dos programas: para quem, sob quais circunstâncias e quais componentes são mais efetivos?

Outro artigo publicado no ano de 2007 para realizar uma revisão bibliográfica sobre a SB não só no Brasil como também em outros países, considerados prevalência, fatores de risco, associação com outros transtornos psiquiátricos e consequências para a empresa em que trabalha e para o próprio indivíduo.

Em conclusão, obteve-se desta pesquisa o seguinte resultado: a prevalência não tem níveis determinados conclusivamente, porém os estudos apontam que acomete uma parcela significativa de indivíduos, variando de aproximadamente $4 \%$ a $85,7 \%$ conforme a população estudada. Chegou-se à concluir que os efeitos de Burnout prejudicam o profissional em três dimensões sendo individual no âmbito físico, mental, profissional e social; profissional no tocante à falta de eficácia, contato impessoal com colegas e clientes e organizacional se apresentando na forma de conflitos, rotatividade absenteísmo e baixa qualidade dos serviços. A pesquisa sugere mais estudos para que através de evidências científicas sejam implementadas mudanças positivas nas organizações.

Uma das revisões selecionadas publicada no ano de 2008, analisou a produção ciêntífica sobre a SB no Brasil através de busca em bases de dados obteve-se 27 artigos sendo que desses observou-se 
que a maioria predominante foi de relatos de pesquisa e as categorias mais estudadas são de professores e de profissionais da saúde.

Concluindo que a SB apesar de contemplada pelo Ministério de Saúde, é ainda pouco conhecida e divulgada devendo-se à cultura da subsistência, que pouco valoriza o bem estar do colaborador, as ações preventivas poderiam beneficiar empresários e trabalhadores, porém as dificuldades do trabalho tendem a ser naturalizadas.

O estudo aponta ser necessária uma melhor integração/informação dos profissionais de saúde sobre o tema para a facilitação do diagnóstico e possibilidades de intervenção, refletindo em um contexto sistêmico de relações de trabalho, saúde e produção, será capaz de conferir credibilidade para influir sobre as políticas públicas de trabalho no plano nacional.

$\mathrm{Na}$ categoria atual houve ainda na seleção uma revisão sistemática do ano de 2011. Que objetivou descrever a prevalência da Síndrome de Burnout e avaliar a possível relação entre trabalho dos professores de ensino médio e fundamental e a síndrome supracitada,obteve-se como resultado uma elevada prevalência de SB entre professores do ensino médio e fundamental e revelaram associação entre condições de trabalho docente como carga horária de trabalho dentro e fora de sala de aula, número de alunos por sala e a SB.

A última revisão selecionada foi publicada no ano de 2012 e foi realizada com o intuito de apresentar reflexões acerca dos principais fatores de risco para o desenvolvimento da Síndrome de Burnout entre os profissionais docentes, para de compreender sua decorrência dentro de um processo de desgaste físico-emocional dentro do trabalho.

Os resultados do estudo apontaram para a carência de estudos realizados na área. E a necessidade de aprofundamento sobra a manifestação do estresse ocupacional entre professores e compreender e esclarecer problemas enfrentados por esta categoria profissional como: insatisfação profissional decorrente de falta de reconhecimento, o absenteísmo, baixo rendimento no trabalho e doenças ocupacionais que incluem o Burnout.

\section{Conclusão}

Após a análise criteriosa dos artigos supra citados, conclui-se que a Síndome de Burnout influi diretamente na qualidade de vida dos professores, provocando cansaço, irritabilidade, pressão alta, e até, em alguns casos, a evasão do trabalho. Os sintomas nem sempre são percebidos de imediato, mas de acordo com o conjunto de artigos pesquisados, são provocados pela alta carga de trabalho a qual são submetidos os professores, o aumento das cobranças sobre seus trabalhos, o excesso de horas de 
aulas ministradas, a sensação de impotência na tentativa de adquirir uma melhor situação financeira e/ou profissional. Também ficou evidenciado com as pesquisas que alguns aspectos influenciam nos sintomas, tais como, idade, tempo de serviço e questões culturais.

É recomendável que se façam novas pesquisas e estudos sobre o assunto, visto que a Síndrome de Burnout ainda se mostra pouco explorada diante da imensidão de variáveis que podem acometer, através de sintomas, os professores e que se transformam em motivo de estresse, afetando a qualidade de vida destes profissionais. Observou-se ainda a necessidade de mais estudos e em novas dimensões para fundamentar melhor mudanças preventivas nas organizações, visto que a Síndrome de Burnout afeta tanto o profissional como a empresa/instituição/escola comprometendo os resultados e também para chamar atenção da necessidade de políticas públicas voltadas para a prevenção e assistência da população acometida pelo estresse ocupacional .

\section{Referências}

ANDRADE, P. S. e CARDOSO, T. A. O. Prazer e Dor na Docência: Revisão Bibliográfica sobre a Síndrome de Burnout. Saúde Social. São Paulo, v. 21, n. 1, p. 129-140, 2012.

BATISTA, J. B. V, et. al. Prevalência da Síndrome de Burnout e fatores sociodemográficos e laborais em professores de escolas municipais da cidade de João Pessoa, PB. Revista Brasileira Epidemiol, v. 13, n 3, p 502-512, 2010.

CARLOTTO, M. S e CÂMARA S. G. Análise da Produção Científica sobre a Síndrome de Burnout no Brasil. Revista Psico. v. 39, n. 2, p. 152-158, 2008.

CARLOTTO, M. S e CÂMARA S. G. Preditores da Síndrome de Burnout em professores. Revista Semestral da Associação Brasileira de Psicologia Escolar e Educacional (ABRAPEE), v. II, n. I, p.101-110, jan/jun 2007.

CARLOTTO, M. S e CÂMARA S. G. Síndrome de Burnout e estratégias de enfrentamento em professores de escolas públicas e privadas. Psicologia da Educação. São Paulo, v. 26, p. 29-46, $1^{\circ}$ semestre de 2008,

CARLOTTO, M. S. e PALAZZO, L. S. Síndrome de Burnout e fatores associados: um estudo epidemiológico com professores. Cadernos de Saúde pública, Rio de Janeiro, v. 22, n. 5, p. 10171026, 2006.

CARLOTTO, M. S. Síndrome de Burnout Professores: Prevalência e Fatores Associados. Psicologia: Teoria e Pesquisa. V. 27, n. 4, p. 403-410, 2011.

CARLOTTO, M. S. Síndrome de Burnout: diferenças segundo níveis de ensino. Psico. v. 41, n. 4, p. 495-502, out/dez, 2010.

FARIAS, G.O., et. al. Qualidade de Vida no Trabalho e Síndrome de Burnout em professores de educação física do Estado do Rio Grande do Sul, Brasil. Revista Brasileira de Atividade Física \& Saúde. v. 4, n. 2, p 115-122, 2009. 
GONÇALVES, T. B., et al. Prevalência de Síndrome de Burnout em Professores Médicos de uma Universidade Pública em Belém do Pará. 2012.

JIMENEZ, B.M., et al. A Avaliação do Burnout em professores. Comparação de Instrumentos: CBP-R e MBI-ed. Psicologia em Estudo, Maringá, v.7, n. 1, p.11-19, jan/jun. 2002.

MARTINS, K. R. L. Síndrome de Burnout: estudo com professores da rede estadual de ensino médio de Campina Grande. Trabalho de Conclusão de Curso (Graduação em Psicologia) Universidade Estadual da Paraíba, Centro de Ciências Biológicas e da Saúde, 2013.

MENDONÇA, V. L. G., COELHO. J. A. P. M., JÚCA. M. J. Síndrome Burnout em Médicos Docentes de uma Instituição Pública. Psicologia em Pesquisa. v. 6, n. 2, p. 90-100, 2012.

MINISTÉRIO DA SAÚDE. Portaria $n^{\circ}$ 1.339/GM, de 18 de novembro de 1999: dispõe sobre lista de doenças relacionadas ao trabalho. Diário Oficial da União, Brasília, 1999.

MURTA, S. G. Programas de manejo de estresse ocupacional: uma revisão sistemática de literatura. Revista Brasileira de Terapia Comportamental e Cognitiva. v.VII, n. 2, p. 159-177, 2005.

SANTOS, A. A. e SOBRINHO, C. L. N. Revisão Sistemática da Prevalência da Síndrome de Burnout em Professores do Ensino Fundamental e Médio. Revista Baiana de Saúde Pública. v. 35, n.2, p.299$319,2011$.

SILVA, G. N. e CARLOTTO, M. S. Síndrome de Burnout: um estudo com professores de rede pública. Psicologia Escolar e Educacional, v. 7, n.2, p. 145-153, 2003.

TEIXEIRA, F. G., SILVA, M. R. S. e MEDEIROS, G. L. Síndrome de Burnout - a interface entre o trabalho na área da educação e na enfermagem. Revista de Enfermagem Referência. v. III, n. 2, p.101-109, 2010.

TRIGO, T.R. et al. Revisão de Literatura: Síndrome de Burnout ou estafa profissional e os transtornos psiquiátricos. Revista Psiquiatria Clínica. V. 34 n 5, p. 223-233, 2007.

VIEIRA, I. Conceitos de burnout: questões atuais da pesquisa e a contribuição da clínica. Revista Brasileira de Saúde Ocupacional. São Paulo, v. 35, p. 269-276, 2010.

\section{Como citar esse artigo (ABNT):}

CAMPELO, Maria Paula S.; OLIVEIRA, Sidney M. Análise da Produção sobre a Síndrome de Burnout em professores, de 2002 a 2013. Id on Line Revista de Psicologia, Julho de 2014, vol.8, n.23, p. 243-253. ISSN 1981-1179. 